\title{
Prevalence of Cigarette Smoking among Adolescents in Ras Tanura Community, Saudi Arabia: A School-based Cross-Sectional Study
}

\author{
Article by Racheal Adepeju Ajibade \\ Public Health, Texila American university \\ E-mail: ajibaderacheal@yahoo.com
}

\begin{abstract}
Background: The proportion of youth involves in cigarette smoking has been escalating in recent years a slight few was known regarding its epidemiology in Rastanura area. The goal of this study was to discover the prevalence of cigarette smoking among adolescents in Rastanura Community, Saudi Arabia.

Method: Primary mode of data collection was used through a well-administered questionnaire to the adolescent both in school and the hospital premises. A school-based cross-sectional workup was conducted during the period of February to October 2018 of which 6 governmental intermediates and high schools' pupils participated. A total of two hundred and fifty (250) questionnaires was administered. The prevalence of smoking was appraised and statistical analysis was executed including chi-square, frequency, and percentage. The responses from the survey were analyzed using SPSS 20.

Result: The overall feedback rate was 82\%,30.2\% of the respondent reported having tried smoking $29.9 \%$ were male while $4.4 \%$ female where $69.8 \%$ never smoked. The investigations on the rate of frequency of smoking among adolescents in the study area shown with X2 =317.837, $p<0.05$.

Conclusion: Findings from our survey show that the level of smoking among male adolescent is higher than their female counterpart. The adolescents in the study area are aware of negative impact of tobacco, but are still addicted to the act despite the knowledge of the danger it portrays. Therefore, parents and guardian should take up the responsibility to reduce their ward's exposure to tobacco product and excess money that could be used for extravagant spending. Keywords: Adolescent, Feedback, Prevalence, Smoking, Saudi Arabia.
\end{abstract}

\section{Introduction}

\section{Background of the study}

Globally, tobacco is a deadly drug which has negative impact on the human body with tendency of inducing close relative into the dangerous act. The world health organization in 2011 found that death caused by smoking-related disease was more than that cause by all infectious diseases altogether. According to the report, if urgent attention is not put in place to reverse this trend, the mortality rate by 2030 will increase by $250 \%$, among citizens of developing and under-developed nations. Smoking is one of the leading preventable cause of death and disease of the $21^{\text {st }}$ century (Jha p \& Peto R. undated). Although, smoking is a habit that can be easily corrected at its early stage, but if not given the needed attention by parent or guardians this act may become addictive.

Adolescences witness various levels of changes - physical, mental, psychosexual and social (Cicchetti D, Toth SL 1998) - in their bodies as they grow up, this encourage them to involve in various act in order to give them recognition in the community. The teenager at this developmental stage is socialized through various socialization agents - parents, peer groups, family members - which encourages him/her to discover himself/herself and to determine the social integration and acceptance within the community. Studies shows that a handful of adult smokers were initiated during their adolescent age (Park Sh 2009) habit like smoking acquired at the early stage of life has tendency of being kept to adulthood which are usually difficult to correct. This habit comes with unhealthy behaviour such as use of illicit drugs, pre-marital sex and alcohol usage (Lim et al 2017). Separated parents and living in non-standard family structures such as single parent families have been linked with an exposure to unpleasant behaviors among youths such as smoking, drinking alcohol, substance abuse, and risky sexual behaviors (Kirby, 2002). 
Smokers are usually not unaware of the risk and resulting effect of the consumption of tobacco and its derivatives but this habit seems unstoppable - nicotine is a drug that is found in tobacco plant which is the main ingredient necessary for the addiction to tobacco products, including cigarettes. The severance of this issue is further aggravated by the fact that children do not have the ability to prevent themselves from a smoky environment and to move away from where smokers are (Thomson 2006). Adolescence is implicated by its surrounding socialization agents through intense stress and various psychogenic factors leading to the emergence of psychiatric disorders, immoral and antisocial behavior in teenagers (Cicchetti D, Toth SL 1998).

For the past 20years, the school environment has been the primary focus point to molding the behavior of adolescents by exposing them to the danger in the use of tobacco and its substance, therefore, reducing the exposure of teenagers to the unhealthy behavior. Smoking is not just harmful to the smoker but also to those that around which are known to be secondhand smoke (SHS) also term "environmental tobacco smoke". (ETS)There are 2 forms of smoke that comes from burning tobacco written by American cancer society2015 these are Mainstream smoke: The smoke exhaled by the smoker whereas Sidestream smoke are the smoke that come out from the lighted end of a cigarette, pipe, cigar or tobacco burning in a hookah. This type of smoke has higher concentrations of cancer-causing agents (carcinogens) and is more toxic than mainstream smoke. It also has smaller particles than mainstream smoke. These smaller particles make their way into the lungs and the body's cells more easily.

When non-smokers are exposed to SHS it's called involuntary smoking or passive smoking. On-smokers who breathe in SHS take in nicotine and toxic chemicals the same way smokers do. The more SHS you breathe, the higher the levels of these harmful chemicals in your body. (American cancer society, Nov 11 2015), Centers for Disease Control and Prevention. Secondhand Smoke (SHS) Facts. August 20, 2015.

Smokers can be divided into: direct, indirect (involuntary smoking or passive smoking) and thirdhand smoke (THS) or residual tobacco smokers. The direct smoker is the person engaging in the act of smoking. Research does show that particles from secondhand tobacco smoke can settle in dust and on surfaces and remain there long after the smoke is gone. Some studies suggest the particles can last for months. Even though it's no longer in the form of smoke, researchers often call this thirdhand smoke (THS) or residual tobacco smoke.

According to the US department of health and human service, smoking is harmful to most organs of the body causing cancers of the lung, esophagus, larynx, mouth, throat, kidney, bladder, pancreas, stomach, and cervix, as well as acute myeloid leukemia. Research has shown that cigarette smoking can lead to premature death.

\section{Statement of the problem}

Prevention of smoking among the population of any country should be paramount on the agenda of any forward-looking government. Smoking prevention program should be directed towards addressing the issue among the general population (Hedman, Anders, Matthew Perzanowski, Sundberg, Eva Ronmark 2007). More so, tobacco consumption varies among different gender, culture, and province (region) of any nation. Hruba et al 2011 suggested "Smoke Free Homes" program which will restrict or totally prohibit smoking in homes where children below the age of 10 lives. A research conducted among Czech children to evaluate the success of an educational intervention programme called "Non-smoking is a Norm" designed for primary school age children shows that $75 \%$ of children ranging between 6 and 11years are exposed to smokers who are intimate family members, close to $30 \%$ of this children have parents that use tobacco, with $20 \%$ of them having grandparents who smokes while $10 \%$ have both grandparent and parents who consume tobacco (Hruba et al 2011). Similarly, (Bromley, Sproston \& Shelton 2005) found out from the research conducted in Scotland that more than $80 \%$ of children between the ages of 8 and 15 are exposed to smoking most especially among their closest family members. In the US, King 2009, concluded that the number of children exposed to tobacco smokes and its derivative in their immediate residence are five times more than adults who are exposed to the same within a period of 20 years. Also, in the US, the Center for 
Disease Control and prevention (CDC) in their study found that $7.9 \%$ of junior high school students and $23.2 \%$ for high school student are engaged in smoking. In spite of the various anti-smoking projects embarked upon by government at various levels; many adolescents are being initiated to smoking at school age (Urrutia-Pereira, Oliano, Arada, Mallol \& Sole 2016) Alexander et al., 2001 in their findings reported that more than $80 \%$ of adult smokers began cigarette smoking at or before the age of eight.

Various studies have shown high prevalence of tobacco consumption among females (Schofield, Lynagh \& Misha 2003; Precht, Keiding, \& Madsen 2003; Larsson L 1995). According to Linnea et al 2006 the patterns of tobacco use varies significantly between male and females; more so, they concluded that the use of tobacco substances and snuff are common among boys of adolescent age while the girls of the age range are used to smoking in Northern Sweden. In Saudi Arabia, among individuals aged 15 years or older, approximately $37.6 \%$ of males and 6\% of females are tobacco current smokers (World Health Organization 2008). Conversely, Mohammed (2013) suggests smoking epidemic among boys in Saudi Arabia is still in the early stage, providing great opportunity for preventive actions to the taken in this line in order to prevent the epidemics from aggravating.

However, reasons have been put forward by researchers as to the factors accounting for the consumption of tobacco among adolescent. In the study conducted by Urrutia-Pereira et al 2016, factors such as having friends who smokes, easy access to cigarettes at home, having cigarette offered by friends etc. Vassilopoulos, Gourgoulianis, Hatzoglou and Roupa (2015) were of the opinion that lack of proper orientation on the danger that smoking has to human health is a factor contributing to the increase in smoking habit among adolescents. The influence of advert of tobacco product is also a significant factor accounting for the increase in the push of young people to smoking (Vassilopoulos et al 2015). At least, $3 \%$ of adolescent in the USA who had once seen a tobacco advert will end up smoking in future Wakefield et al (2016). According to Al Nohair (2011), 28.6\% of secondary school students in National Guard area of Riyadh smokes, the ubiquitous reasons given for this are, approximately $82 \%$ were of the opinion that it was due to the available free time, $63 \%$ said for stress relief while $62 \%$ said it was because their teacher's smokes. Contrarily, Al-Haddad \& Hamadeh (2003) believes that family history of smoking accounts for adolescents smoking. According to the report of Al-Zalabani and Kasim (2015) the prevalence of cigarette smoking in secondary school students ranged from $12 \%$ to $29.8 \%$, and among university students, it ranged from $2.4 \%$ to $37 \%$, with female and medical students' constituting the least percentage. The literature is therefore inconclusive has to which factor is significant or with greater impact at attracting adolescents to smoking.

To the best of our knowledge little work has been done in Saudi Arabia in relation to the effect of smoking on adolescent health, with none conducted on the Rastanura community, with dominant strength of young people. Nevertheless, this study aims at providing an empirical based result which will enable policy makers in formulating and implementing suitable policies in the public interest as to reducing the incidence of smoking related death among adolescents in Saudi Arabia. Furthermore, female Saudi Arabian youth are a difficult population to access which has been a limitation to the generalization of existing result. This study will therefore offer a rare look into the health behavior of Saudi Arabian girls with respect to their smoking habit which has universally been neglected by past works.

\section{Research question}

This study aims at addressing the following research questions;

What is the level of exposure of different gender to smoking in the study area?

What are the smoking rate of adolescents in the study area?

What is the nature of relationship between smokers and their health condition in the study area?

\section{Objective of the study}

The broad objective of this study is to examine the effect of smoking among adolescent in Rastanura community, Saudi Arabia. The specific objectives are to;

1. Explore the smoking habit of male and female in the study area; 
DOI: 10.21522/TIJPH.2013.SE.19.01.Art004

ISSN: 2520-3134

2. Evaluate rate of smoking among adolescent in the study area;

3. Investigate the prevalence of tobacco product consumption among adolescents in the study area

\section{Hypothesis}

This study will consider the following research hypothesis:

\section{Hypothesis 1}

$\mathrm{H}_{0}$ : Rastanura female Smoke habit is the same with their male peers.

$\mathrm{H}_{1}$ : Rastanura female smokes less than their male peers.

\section{Hypothesis 2}

$\mathbf{H}_{0:}$ Rastanura adolescents' smokes frequently

$\mathbf{H}_{1:}$ Rastanura adolescents do not smokes frequently

\section{Scope of the study}

This study examined the smoking habit of adolescent in Rastanura, Saudi Arabia. The population of this study was drawn from the secondary schools in the Rastanura with emphasis on adolescents or students with age ranging from 8 to 10 years. A sample of 250 adolescents was selected using a random sampling technique. This sample was used to make generalization on the smoking habit of the population.

\section{Gaps from the literature}

In summary, all the studies have examined the prevalence and factors responsible for the smoking habit and behaviours of adolescent in various regions, states and countries. A number of factors have been put forward as accounting for this unhealthy behavior among adolescent in the regions. Based on this, the study intends to contribute to the body of knowledge by further examining this habit among adolescents in Rastanura, Saudi Arabia. This will help come about valid factors responsible for the prevalence of smoking in the region.

\section{Methodology}

\section{Research design and methods}

This study made use of primary data. Data was collected using a self-administer questionnaires which was distributed to intermediate and high school students in Rastanura community. Categorical and quantitative data was obtained. The data will be gathered from school students and hospital patients based on their interaction with the youth in the community. The survey was structured to collect basic sociodemographic information, smoking -related factors and tobacco smoking history, peer behavior and individual attitude towards smoking and risk perception. The survey questions were taken from the National Youth Tobacco Survey and the Centers for Disease Control and Prevention question database. Using these tested questions lends validity to this study, and provided a basis for comparison with national survey result. Furthermore, the study collected data from respondents on smoking practices and their view-points.

\section{Study area}

Rastanura is largest oil shipping center in eastern province. It is located south of modern industries port city, Jubail, and North of Tarut with a total population of 73,933 people. RasTanura, also spelled Ras Tannura, Arabic Ra's Al-Tannūrah. Developed by the Arabian American Oil Company (now Saudi Aramco) after the discovery of nearby petroleum deposits in the 1930s, it is now a principal Persian Gulf terminal of pipelines and has a modern port capable of accommodating the largest tankers. The town also has a refinery and storage tanks as well as hydro formers, producing high-octane gasoline. Aramco operates an industrial-training school and hospital. 
Geographically, the Rastanura complex is located south of the modern industrial port city of Jubail (formerly a fishing village) and north of Tarut Bay from the old port city of (Al-) Dammam. Although, Ras Tanura's port area is located on a small peninsula, due to modern oil tankers' need for deeper water, Saudi Aramco has built numerous artificial islands for easier docking. Location of Ras Tanura Coordinates: $26^{\circ} 39^{\prime} \mathrm{N} 50^{\circ} 10^{\prime}$ E. Postal Code 32819 Area code(s)+966-13.

Ras Tanura is connected by a single two-lane highway with the Dhahran-Jubail Highway which links it with neighboring cities such as Jubail and Dammam as well as with the regional Aramco headquarters in Dhahran. Although there is a small airport in the city Ras Tanura Airport, commercial air transportation is provided by King Fahd International Airport in Dammam as the local one is for the exclusive use of Saudi Aramco, mainly helicopters. The distance from the city center to the terminal in Dammam Airport is approximately $50 \mathrm{~km}(31 \mathrm{mi})$. However, a current project is ongoing to shorten that distance to $40 \mathrm{~km}(25$ $\mathrm{mi})$ if the new road is completed.

\section{Target population}

A total population of 9747 students, female and male, attends both government and private school in Rastanura. Out of this, 2074 of them falls between the age of 9 and 19 in both intermediate and high schools; which will constitute the focus group for this study. According to the National Youth Tobacco Survey and the Centers for Disease Control and Prevention question database, a smoker is defined as one who had at any time smoked a cigarette or who had, had one or two puff. While current smoker is defined as one who had taken a puff, or, smoked cigarette in the last 30-days, proceeding the day, of completing the questionnaire.

\section{Sampling size and sampling method}

The study adopted a purposive sampling technique, this is a type of non-probabilistic sampling technique where members of the sample will be selected based on researchers' judgment or requisite information gather about the respondent. The study will purposively select a total of 250 students from the 2074 adolescents in various intermediate and high schools in Rastanura, Saudi Arabia.

\section{Survey instrument}

Intermediate and secondary school surveyed using the Smoking Behavior among College Students Survey found in Appendix A of the report. The questionnaire from the survey was adopted for this study with little modification. Students that were found at the schools' premises and hospital community provided responses to the questions. In addition, a means of survey design and distribution, analysis and reporting tools that will provide basic statistical values and allow for the creation of tables and cross-sectional comparisons. The survey will begin with a consent form; students will be required to read the information and answer, "I agree" to verify that they fall between the ages 9 and 19. And that they had read and understood the form, aware of their rights as participants, and, agreed to participate in the research; before they respond to the questionnaire.

\section{Technique of data analysis}

The responses from the field survey was analyzed, summarized and interpreted with the aid of both descriptive statistics and statistical techniques. Descriptive analysis will be used to describe percentage and number of distribution of the respondents by socio-economic/demographic characteristics. To examine the relationship between explanatory variables and dependent variable; Chi-square was employed which is effective in testing the relationship between two or more categorical variables. In order to achieve a valid response using the instrument, the questions were tailored to achieve the objective of the study. The implementation will be done by using statistical software -SPSS 20 edition. 
DOI: 10.21522/TIJPH.2013.SE.19.01.Art004

ISSN: 2520-3134

\section{Results and discussion}

This chapter gives a detail analysis of data and interpretation of the results. This chapter is divided into various sections which include the analysis and interpretation of the demographic data and statistical result. The analysis in this chapter was performed using SPSS 20.

\section{Analysis of respondents}

The questionnaires designed on the "SMOKING HABIT AMONG THE ADOLESCENT IN RASTANURA COMMUNITY" were administered to two hundred and fifty (250) adolescents in the study area. In order to ensure quick responses and avoid losses, copies of the questionnaires were administered by the researcher to respondents. Of the entire two hundred and fifty (250) questionnaires administered, the researcher was able to obtain back two hundred and five (205), representing eighty percent (82\%) success rate; while the remaining forty-five (45) consisting twenty percent (18\%) were not recovered due to some logistics and unavailability of the students at the time of collection. This is shown in the table below:

Table 1. Analysis of questionnaires returned

\begin{tabular}{|l|l|l|l|}
\hline Questionnaire & Frequency & Percentage (\%) & Cumulative Percentage (\%) \\
\hline Returned & 205 & 82 & 82 \\
Not Returned & 45 & 18 & 100 \\
\hline Administered & 250 & 100 & \\
\hline
\end{tabular}

Source: Field survey 2018

\section{Background information of respondents}

\section{Age distribution of respondents}

The analysis of the survey in table 4.2.1 shows the age of the adolescents. The age distribution of respondent's shows that $57.1 \%$ of the respondents were of age 8 to $10,22.9 \%$ of the respondents were between 11 and 13 years, while $20 \%$ of respondents have their ages ranging between 14 and 16years. By implication, the survey has covered a wide range of age bracket within the adolescent age; this will help generate a valid conclusion on the smoking habit of adolescents in the study area. This is consistent with the finding of Dahlui et al (2015), which suggests that smoking is prevalent in children of age 11 and below.

Table 2. Age distribution of respondents.

\begin{tabular}{|l|l|l|}
\hline Age Range & Frequency & Percent \\
\hline $8-10$ & 117 & 57.1 \\
\hline $11-13$ & 47 & 22.9 \\
\hline $14-16$ & 41 & 20.0 \\
\hline Total & 205 & 100.0 \\
\hline
\end{tabular}

Source: Field survey 2018

\section{Sex distribution of respondent}

Information relating to gender characteristics shows that $74.6 \%$ were male and $25.4 \%$ were female. Majority of the respondents are male this is due to the restricted access to female in the study area. According to Al-Zalabani et al (2015), sex is an important determinant on a person's smoking habit. 
Table 3. Sex distribution of respondent

\begin{tabular}{|l|l|l|}
\hline Sex & Frequency & Percent \\
\hline MALE & 153 & 74.6 \\
\hline FEMALE & 52 & 25.4 \\
\hline Total & 205 & 100.0 \\
\hline
\end{tabular}

Source: Field survey 2018.

\section{Grade level of respondents}

Table 3 shows the grade of the respondents on review. $26.3 \%$ of the adolescents are in level below grade $2,18.5 \%$ are within the grade range of 3 to 5 while majority of the adolescents representing 55.1\% are in class grade of 6 to 8. By implication, most of the adolescents used for the survey are knowledgeable and would be able to give reliable responses on their smoking habit.

Table 4. Grade of Respondents

\begin{tabular}{|l|l|l|}
\hline GRADE LEVEL & Frequency & Percent \\
\hline $0-2$ & 54 & 26.3 \\
\hline $3-5$ & 38 & 18.5 \\
\hline $6-8$ & 113 & 55.1 \\
\hline Total & 205 & 100.0 \\
\hline
\end{tabular}

Source: Field survey 2018.

\section{Cash available to respondent for free spending}

According to table 4.2 .5 about 1 in 2 (42.4 percent) of the adolescents in the study area reported that they do not have any money on them for free purchase in last 30days prior to the time of the survey. 5.9\% reported they have between 1 and 5 Riyals, 9.3\% reported having between 6 to 10 Riyals, $2 \%$ having 11 to 20 Riyals, whereas $5.9 \%$ have between 21 to 50 Riyals. While a significant percent (34.6 percent) have more than 50 Riyals to spend freely on monthly basis.

Table 5. The amount of cash available for free purchase in the last 30days

\begin{tabular}{|l|l|l|}
\hline Variable & Frequency & Percent \\
\hline None & 87 & 42.4 \\
\hline 1-5 Riyals & 12 & 5.9 \\
\hline 6-10 Riyals & 19 & 9.3 \\
\hline 11-20 Riyals & 4 & 2.0 \\
\hline 21-50 Riyals & 12 & 5.9 \\
\hline$>50$ Riyals & 71 & 34.6 \\
\hline Total & 205 & 100.0 \\
\hline
\end{tabular}

Source: Field survey 2018

\section{Smoking habit of male and female in the study area}

This section will help to achieve objective one of this study- which is to establish the smoking habit of male and female in the study area. Table 4.3 summarizes the adolescent's response in relation to the smoking habit of different gender in the study area. A total of $30.2 \%$ of the respondent reported having tried smoking, out of this $25.9 \%$ are male while $4.4 \%$ are female, and whereas $69.8 \%$ of the adolescent under survey revealed that they had never tried smoking before.

When asked about whether or not the respondent will like to smoke in the nearest future, $23.4 \%$ reported that they have already tried smoking with $19.5 \%$ of the sampled population male while 
DOI: 10.21522/TIJPH.2013.SE.19.01.Art004

ISSN: 2520-3134

$3.9 \%$ female. More so, $6.3 \%$ of male revealed that they will attempt smoking soon with $0.5 \%$ of female sharing this opinion. However, $69.8 \%$ reported that they may not try smoking soon.

Furthermore, the table also shows the answers of the respondents when asked about the tendency of smoking cigarette in the next year. $18.5 \%$ opined that they will surely smoking cigarette in the next year, with $16.1 \%$ representing male and $2.4 \%$ female. Additionally, $8.3 \%$ of male revealed that they might smoke cigarette in the next year with $1 \%$ of female sharing the same opinion. Majority of respondent $59 \%$ believes the may smoke in the next year, while $13.2 \%$ are so sure of not smoking within the next one year.

The result of the findings also shows the impact of peer relationship on adolescent smoking habit, $22 \%$ of the respondent are so sure that they will smoke if their best friend introduces them to it; $19 \%$ of this response came from male while $2.9 \%$ came from female. Also, $6.3 \%$ of the respondents will probably smoke if it has been introduced to them by their best friend. More than half $66.8 \%$ said they probably not smoke even it is offered to them by their best friend. Whereas, only $4.9 \%$ are so sure of not being introduce to smoking by friends. This finding is consistent with the work of Saad et al (2015) who identified smoker friends as an important determinant of smoking among adolescent.

This study reveals the number of cigarettes smoked by respondent, $69 \%$ reported they not smoked at all. 3.4\% have smoked less than a stick, $4.4 \%$ have smoked a stick, and $4.9 \%$ have smoked between 6 and 99 sticks. However, a significant minority $17.6 \%$ have smoked more than 100 sticks of cigarette.

Nevertheless, this study reveals that smoking is rampant among male adolescent in the study than their female counterpart. This result is in line with the work of Fida and Abdelmoneim (2013); Al-Zalabani and Kasim (2015).

Table 4.3. Response on the smoking habit of male and female in the study area

\begin{tabular}{|c|c|c|c|}
\hline \multirow[t]{2}{*}{ Variables } & \multicolumn{2}{|l|}{ Sex } & \multirow[b]{2}{*}{ Total } \\
\hline & Male & Female & \\
\hline $\begin{array}{l}\text { Have ever tried smoking cigarette? } \\
\text { YES } \\
\text { NO }\end{array}$ & $\begin{array}{l}53(25.9) \\
100(48.8)\end{array}$ & $\begin{array}{l}9(4.4) \\
43(21)\end{array}$ & $\begin{array}{l}62(30.2) \\
143(69.8)\end{array}$ \\
\hline $\begin{array}{l}\text { Will you try to smoke soon? } \\
\text { I have already tried smoking cigarette } \\
\text { YES } \\
\text { NO }\end{array}$ & $\begin{array}{l}40(19.5) \\
13(6.3) \\
100(48.8)\end{array}$ & $\begin{array}{l}8(3.9) \\
1(0.5) \\
43(21.0)\end{array}$ & $\begin{array}{l}48(23.4) \\
14(6.8) \\
143(69.8)\end{array}$ \\
\hline $\begin{array}{l}\text { Will smoke a cigarette in the next year? } \\
\text { Definitely Yes } \\
\text { Probably Yes } \\
\text { Probably No } \\
\text { Definitely No }\end{array}$ & $\begin{array}{l}33(16.1) \\
17(8.3) \\
83(40.5) \\
20(9.8) \\
\end{array}$ & $\begin{array}{l}5(2.4) \\
2(1.0) \\
38(18.5) \\
7(3.4) \\
\end{array}$ & $\begin{array}{l}38(18.5) \\
19(9.3) \\
121(59.0) \\
27(13.2) \\
\end{array}$ \\
\hline $\begin{array}{l}\text { If your best friend offers you a cigarette } \\
\text { would you smoke? } \\
\text { Definitely Yes } \\
\text { Probably Yes } \\
\text { Probably No } \\
\text { Definitely No } \\
\end{array}$ & $\begin{array}{l}39(19.0) \\
11(5.4) \\
97(47.3) \\
6(2.9) \\
\end{array}$ & $\begin{array}{l}6(2.9) \\
2(1.0) \\
40(19.5) \\
4(2.0)\end{array}$ & $\begin{array}{l}45(22.0) \\
13(6.3) \\
137(66.8) \\
10(4.9) \\
\end{array}$ \\
\hline $\begin{array}{l}\text { Number of cigarette ever smoked } \\
\text { Never } \\
<1 \text { cigarette }\end{array}$ & $\begin{array}{l}101(49.3) \\
5(2.4)\end{array}$ & $\begin{array}{l}42(20.5) \\
2(1.0)\end{array}$ & $\begin{array}{l}143(69.8) \\
7(3.4)\end{array}$ \\
\hline
\end{tabular}




\begin{tabular}{|l|l|l|l|}
\hline 1 cigarette & $8(3.9)$ & $1(0.5)$ & $9(4.4)$ \\
$2-5$ cigarettes & $0(0.0)$ & $0(0.0)$ & $0(0.0)$ \\
$6-15$ cigarettes & $1(0.5)$ & $0(0.0)$ & $1(0.5)$ \\
$16-25$ cigarettes & $3(1.5)$ & $0(0.0)$ & $3(1.5)$ \\
$26-99$ cigarettes & $3(1.5)$ & $3(1.5)$ & $6(2.9)$ \\
$>100$ cigarettes & $32(15.0)$ & $4(2.0)$ & $36(17.6)$ \\
\hline
\end{tabular}

Source: Field survey 2018

\section{Rate of smoking among adolescent smokers in the study area}

This section aims at examining how frequent adolescents in the study area smoke, this will help achieve objective two of this study.

Table 4.4.1 shows the response of sampled adolescent that has once tried smoking. From the survey 20.97 percent of the adolescent who smokes have taken less than 1 cigarette, 6.45 percent at least 1 cigarette, 8.06 percent had taken between 2 to 5 cigarette, 6 adolescent representing 9.68 percent had taken between 26 to 99 cigarette while majority of the respondent representing 50 percent had consumed more than 100 cigarettes.

Also, the response of the sample adolescent who smokes indicate that in the last 30days 25.81 percent had not smoked, 14.52 percent smokes for 1 to 2 days, 6.45 percent for 3 to 5 days, 9.68 percent had taken cigarette between 10 to 19 days while large percentage $(37.10$ percent $)$ had smoked in each of the last 30days.

Furthermore, 19.35 percent of the sampled adolescents who smokes had not taken any cigarette in the last 30days, those who consumed less than 1 cigarette and 1 cigarette represent 6.45 percent each of the smoking adolescents in study area. 11.29 percent smokes an average of 2 to 5 cigarettes per day, 17.74 percent smokes between 6 to 10 cigarettes per day, 6.45 percent smoke between 11 to 20 cigarettes while a significant proportion (32.26 percent) smokes more than 20 cigarettes per day.

Table 4.4. Response on rate of smoking among adolescent smokers

\begin{tabular}{|l|l|l|l|l|}
\hline $\begin{array}{l}\text { Have you ever tried smoking? } \\
\text { YES; n=62; CI = 99\% }\end{array}$ & Freq & Percent & $X^{2}$ & P \\
\hline Variables & & & & \\
\hline How many cigarettes have you smoked? & 13 & 20.97 & & \\
<1 cigarette & 4 & 6.45 & & \\
1 cigarette & 5 & 8.06 & & \\
2-5 cigarettes & 1 & 1.61 & & \\
6-15 cigarettes & 2 & 3.23 & & \\
16-25 cigarettes & 6 & 9.68 & & \\
$26-99$ cigarettes & 31 & 50.00 & & \\
$>100$ cigarettes & 62 & 100 & 317.837 & $<0.001$ \\
Total & & & & \\
\hline How many days of the past 30days did & 16 & 25.81 & & \\
you smoke? & 9 & 14.52 & & \\
Oday & 4 & 6.45 & & \\
1-2 days & 2 & 3.23 & & \\
3-5days & 6 & 9.68 & & \\
6-9days & 2 & 3.23 & & \\
10-19days & 23 & 37.10 & & \\
20-29days & & & & \\
\hline
\end{tabular}


DOI: 10.21522/TIJPH.2013.SE.19.01.Art004

ISSN: 2520-3134

\begin{tabular}{|l|l|l|l|l|}
\hline $\begin{array}{l}\text { All 30 days } \\
\text { Total }\end{array}$ & 62 & 100 & 320.916 & $<0.001$ \\
\hline $\begin{array}{l}\text { How many cigarettes do you smoke per } \\
\text { day in the last thirty days? }\end{array}$ & & & & \\
No smoking & 12 & 19.35 & & \\
Less than 1 cigarette & 4 & 6.45 & & \\
1 cigarette & 4 & 6.45 & & \\
$2-5$ cigarettes & 7 & 11.29 & & \\
6-10 cigarettes & 11 & 17.74 & & \\
$11-20$ cigarettes & 4 & 6.45 & & \\
More than 20 & 20 & 32.26 & & \\
Total & 62 & 100 & 330.264 & $<0.001$ \\
\hline
\end{tabular}

Source: Field Survey 2018

\section{Accessibility of respondents to cigarette}

Table 4.4.2 shows how the smoking adolescent get access to the cigarette they smoke, 48.39 percent indicated that they bought it by themselves, 20.97 percent said someone bought cigarette for them. 9.68 percent borrowed money to buy their cigarette, 3.23 percent said they were giving by someone without them asking for it. While 17.74 percent indicated that they got the cigarette from other means without specifying the source of the fund they used in buying them.

\section{Conclusion}

The result of this study is in line with some earlier researchers that believe that the consumption of tobacco among adolescent is increasing and if not properly monitored will lead to personal damages and having negative external spillover effect on the public. Some of the personal damages are: damage to the lung, cancer of the kidney, uterus, lips and heart attack which may further degenerate into loss of life. The effect of increase smoking habit is not just felt by the direct consumer but also by the indirect consumer, whereby causing damages to the health of non-smokers. More so, out-of-pocket spending on health by individual and household increases as a result of the increase in smoking habit. This study points at the fact that all the adolescents in the study area are aware of the resulting negative impact of tobacco, but are still addicted to the act despite the knowledge of the danger it portrays. Therefore, parents and guardian should take up the responsibility to reduce their ward's exposure to tobacco product and excess money that could be used for extravagant spending.

It is also important to point out the impact of cigarette smoking on the environment. Cigarette smoking causes both air and environmental pollution by emitting toxic air pollutants into the environment. Smokes from cigarette contaminates the air and makes air poisonous to the inhaler. Deforestation caused by producer of tobacco and its substance also reduces the amount of tree in the environment and reduces the amount of oxygen in the air while increasing the carbon dioxide in the atmosphere.

Aside that smoking is dangerous to the consumer, environment and the indirect consumer, it also has a negative impact on government spending. There is positive relationship between smoking and government spending. When people-adolescent- smokes it increases the amount of time they have to visit the hospital which will result into increase spending on the provision of health facilities on the part of the government. Furthermore, when smoking increase government needs to embark on extra-budgetary spending in order to create awareness and orientate the public on the negative impact of smoking to the health. In the area of environmental cleaning, government and its agencies need to ensure that the environment is safe and conducive for its citizen. This, causes the public spending to increase.

Now it is therefore recommended that the relevant health and government authorities should embark on wide scale campaign to dissuade young smokers. The government might also impose tax on the tobacco 
and cigarette companies which might leads increase price cigarette and tobacco this might eventually discourage smokers.

Moreover, necessary legislations and monitoring should be put in place mandating tobacco company to write warning of danger of cigarette smoking on their product. This would also have a positive psychological effect on the smoker which might eventually decrease the numbers of young smokers.

\section{References}

[1]. Al-Delaimy W. 2015. E-cigarette use in the past and quitting behavior in the future: a population-based study. Am J Public Health 105(6).

[2]. Alfonso S. 2014. SD Researchers: Electronic Cigarettes Highly Addicting. Coronaldo Patch. Retrieved http://patch.com/california/coronado/sd-researchers-electronic-cigarettes-highly-addicting-0. 79

[3]. Amrock S. 2015. Perception of E-Cigarette Harm and Its Correlation with Use Among U.S. Adolescents. Nicotine Tob Res. 17(3).

[4]. American Bar Association. 2004. Cruel and Unusual Punishment: The Juvenile Death Penalty: Adolescence, Brain Development and Legal Culpability

[5]. American Psychological Association. 2002. Developing Adolescents: A Reference for Professionals http://www.apa.org/pi/families/resources/develop.pdf

[6]. Ayala, G.X.; Mickens, L.; Galindo, P. \& Elder, J.P. 2007. Acculturation and body image perception among Latino youth. Ethnicity \& Health Vol. 12 No. 1, 21-41

[7]. Bancroft, J. \& Reinisch, M. 1990. Adolescence and Puberty. USA. Oxford University Press. Page 9.

[8]. Becket, W. 2004. Quitting Smoking for Life. Australia. Pascal Press. Page 12

[9]. Barbeau A. 2013. Perceived efficacy of e-cigarettes versus nicotine replacement therapy among successful ecigarette users: a qualitative approach. Addict Sci Clin Pract. 8(5).

[10]. Cash, T.F. \& Smolak, L. 2011. Body Image: A Handbook of Science, Practice, and Prevention. Second edition. USA. The Guilford Press. Pages 78-79

[11]. Committee on Adolescent Health Care Services and Models of Care for Treatment. 2008. Adolescent Health Services: Missing Opportunities. USA. National Academic Press. Page 17

[12]. Cahn Z. 2011. Electronic cigarettes as a harm reduction strategy for tobacco control: A step forward or a repeat of past mistakes? Journal of Public Health Policy 32: 16-31.

[13]. D’Arcy, L. 2009. Encouraging a Healthy Body Image. The Nemours Foundation. http://kidshealth.org/parent/positive/talk/body_image.html

[14]. Giannakopoulos, G.; Panagiotakos, D.; Mihas, C. \& Tountas, Y. 2009. Adolescent smoking and health-related behaviours:interrelations in a Greek school-based sample Child: Care, Health \& Development Vol. 35 No. 2, 164-170 [15]. Jiloha, R.C. 2008. Taboco Use: Health and Behaviour. India. New Age International Publishers. Page 129.

[16]. Kipke, M.D. 1999. Adolescent Development and the Biology of Puberty: Summary of a Workshop on New Research. USA. National Academies Press. Page 2.

[17]. McCay, W.; Dingwell, H.; Golden, R.N. \& Peterson, F.L. 2009. The Truth about Smoking. Second edition. USA. DWJ Books LLC. Pages 76 - 77

[18]. Mackay, J. \& Eriksen, M. 2002. The Tobacco Atlas. Switzerland. World Health Organization. Swizerland. Pages 34-36. Available at: http://site.ebrary.com.ezproxy.turkuamk.fi/lib/turkuamk/docDetail.action?docID=10021038\&p00=The+Tobacco+At las

[19]. MacDonald, P. 2004. Understanding smoking behaviour in children and adolescents. Paediatric Nursing Vol. 16 No. 3, 26-27

[20]. Price, B. 2009. Body image in adolescents: insights and implications. Paediatric Nursing Vol. 21 No. 5, 38-43. [21]. Orzechowski M. 2014. The Tax Burden on Tobacco. 46.

[22]. Osungbade KO, Oshiname FO. Determinants of cigarette smoking among senior secondary school students in a rural community of Southwest Nigeria. Niger J Med 2008; 17:40-4. 
DOI: 10.21522/TIJPH.2013.SE.19.01.Art004

ISSN: 2520-3134

[23]. Research for International Tobacco Control. 2003. At what cost? The economic impact of Tobacco use on national health systems, societies and indivuals: a summary of methods and findings. RITC: Monograph Series No.1.RITC. Page 21

[24]. Rosado, L.M. 2000. Kids are Different : How Knowledge of Adolescent Development Theory Can Aid DecisionMaking in Court.

[25]. Sofronoff, K.; Dalgleish, L.\& Kosky, R. 2004. Out of Options: A Cognitive Model of Adolescent Suicide and Risk Talking. USA. Cambridge University Press. Pages 60-61

[26]. Sabbah, H.; Vereecken, C.; Abdeen, Z.; Coats, E. \& Maes, L. 2009. Associations of overweight and of weight dissatisfaction among Palestinian adolescents: findings from the national study of Palestinian schoolchildren (HBSCWBG2004). Journal of Human Nutrition \& Dietetics Vol. 22 No. 1, 40-49

[27]. Sarkar, S. \& Andreas, M. 2004. Acceptance of and engagement in risky driving behaviors by teenagers. Adolescence Vol. 39 No.156, 687-700

[28]. UNICEF 2002 Adolescence: $\quad$ A time

http://www.unicef.org/publications/files/pub_adolescence_en.pdf Referred 23.09.2011

[29]. WHO Report on Global Tobacco Epidemic. 2008. MPOWER Package. WHO. Pages 8-12

[30]. Wang, R.; Hsu, H.; Lin, S.; Cheng, C. \& Lee, S. 2010. Risk behaviours among early adolescents: risk and protective factors. Journal of Advanced Nursing Vol 66 No. 2, 313-323

[31]. Wolfe, D.A.; Jaffe, P.G. \& Crooks, C.V. 2006. Adolescent Risk Behaviors: Why Teens Experiment and Strategies to Keep Them Safe. USA. Yale University Press. Page 76.

[32]. Weiss, J.W.; Mouttapa, M.; Cen, S.; Johnson, A. \& Unger, J. 2011. Longitudinal Effects of Hostility, Depression, and Bullying on Adolescent Smoking Initiation Journal of Adolescent Health Vol. 48 Issue 6, 591-596

[33]. Weiss, J.W.; Palmer, P.H.; Chou, C.; Mouttapa, M. \& Johnson, C.A. 2008. Association between psychological factors and adolescent smoking in seven cities in China. International Journal of Behavioral Medicine Vol 15 No.2, $149-156$

[34]. Yoo, J. \& Johnson, K.K.P. 2007. Effects of appearance-related testing on ethnically diverse adolescent girls. Adolescence, Vol. 42 No.166, 353-80 